\title{
Uma odisséia no ciberespaço: $O$ software educacional dos tutoriais aos mundos virtuais
}

\author{
Lucia Maria Martins Giraffa \\ Faculdade de Informática - PUCRS VIRTUAL \\ Mestrado em Educação em Ciências e Matemática \\ Av. Ipiranga 6681 - prédio $40-9^{\circ}$ andar - \\ Porto Alegre - RS - Brasil 90610-900 \\ giraffa@pucrs.br
}

\begin{abstract}
Resumo Quando se analisa os tipos de software educacionais e se critica suas eventuais limitações deve-se cuidar a questão das crenças de Educação e do contexto tecnológico que se professava na época do seu projeto. Logo, não se pode inferir ou medir a qualidade do programa sem levar em consideração o seu contexto. Em tempos de interatividade em dispositivos móveis em larga escala, jogos sofisticados, blogs, mundos virtuais e tantos outros dispositivos disponibilizados a cada dia faz-se necessária uma reflexão e um resgate histórico deste tipo de aplicação. Projetar e implementar um bom programa para fins educacionais não é uma tarefa fácil ou trivial. Isto requer um trabalho em equipe interdisciplinar com competências diversificadas, tanto no aspecto tecnológico quanto no pedagógico. A equipe do projeto deve contemplar pessoas com habilidades complementares e uma visão histórico-contextualizada do que significa desenvolver uma aplicação educacional. Este artigo apresenta uma reflexão acerca dos softwares educacionais considerando uma perspectiva histórica, experiência da autora na gerência e implementação de projetos de software desta modalidade, levando em consideração o impacto da evolução tecnológica no projeto destes sistemas. Apresentam-se também considerações para quem deseja projetar aplicações educacionais considerando-se o ciberespaço como um ambiente virtual de suporte ao ensino e a aprendizagem.
\end{abstract}

Palavras-Chave: Software Educacional, Informática na Educação, Ciberespaço.

\begin{abstract}
The development of educational software is guided by the set of beliefs of those who designed it and the technical resources available in the period the software was developed. Thus, we must consider the technological and historical context the software was developed when analyzing and evaluating educational software. In order to design and to implement such type of software we must count on a heterogeneous team of pedagogical and technical professionals with supplementary skills and knowledge. The understanding regarding historical aspects and educational implications must be considered by the team to better design the software. The professionals involved in the development of an educational software need to understand the complexity and peculiarity intrinsically into such kind of software. This paper presents an historical review of educational software from the technical evolution perspective. This review is also presented based on my personal experience leading the design and development of educational software projects in Brazil. In addition, we point out ideas those who intend to develop educational software considering the virtual learning environment created for the cyberspace.
\end{abstract}

Keywords: Educational Software, Computer Science applied to Education, Cyberspace. 


\section{Introdução}

Veen e Vrakking (2009) apresentam o fenômeno do Homo Zappiens como grande fator de mudança na educação. Esta nova geração faz coisas diferentes e são expoentes de mudanças relacionadas à globalização. Eles se comunicam com seus pares e demais pessoas de forma mais intensa usando o computador, o celular, os iPods, os blogs, os Wikis, as salas de bate-papo na Internet, os jogos em rede e as diversas plataformas de comunicação que a cada dia são criadas. Não se sabe a novidade que vem por ai, mas se sabe que a comunicação interativa é à base de toda oferta tecnológica. As pessoas querem se comunicar a um simples toque de botão. Nada mais natural para quem desde bebê foi estimulado a usar um controle remoto e foi educado que a distancia física não é fator impeditivo para comunicação e a aprendizagem.

Os autores salientam que esta geração se difere de qualquer outra porque cresceu numa era digital. Eles são os primeiros seres digitais que cresceram em um mundo onde a informação e a comunicação estão disponíveis a quase todas as pessoas e podem ser usadas de maneira ativa. A oferta cresce a cada dia e a velocidade com que os artefatos obsoletam assusta os mais conservadores e aqueles que são imigrantes neste ciberespaço (Prensky, 2001).

O ciberespaço, termo utilizado por Lévy (2000) quando se refere ao espaço virtual criado pela grande rede Internet e seus serviços (Web, correio eletrônico, FTP,...), é fruto de um objeto comum, dinâmico, construído, ou pelo menos alimentado, por todos os que o utilizam.

Segundo Elias (2008), o ciberespaço é considerado, a meu ver, um "lugar-máquina", porque é de fato um espaço que concilia dois elementos extremamente importantes; um é a tecnologia, o outro o racionalismo. O ciberespaço é o ponto de reunião de algo que se encontrava fragmentado e deixado ao acaso na modernidade (a tecnologia).

Se este contexto impacta o cotidiano das pessoas, no que tange ao ambiente educacional o impacto é maior. Explico melhor: a escola tradicionalmente leva mais tempo para absorver e incorporar as tendências e as ofertas tecnológicas. No caso da realidade brasileira ela ocorre devido a vários fatores que não fazem parte desta discussão, vamos centrar nossa reflexão na questão da produção do software educacional e seu desafio face ao contexto da cibercultura.

As Tecnologias Digitais (TD) integradas e disseminadas na rede Internet mudaram a forma como se percebe e selecionam os recursos computacionais. A discussão não é mais centrada na escolha do software tão somente e sim em utilizar e selecionar quais dos recursos oferecidos melhor se adaptam e adéquam aos objetivos pedagógicos que o docente possui.
A oferta de recursos é variada. Uma simples pesquisa usando ferramentas de busca como o Google, Yahoo e similares permite-nos encontrar softwares educacionais mais simples (tutoriais) até simuladores e micromundos ${ }^{1}$ onde os alunos podem experimentar no virtual algumas situações que dificilmente vivenciariam no presencial.

No entanto a motivação principal para a modificação da atitude do professor face às possibilidades que as TDs trazem para o cenário educacional se embasa no fato de que os alunos de hoje possuem outra forma de construção do conhecimento do que os professores (a maioria deles) que os acompanham e tutelam (Lévy, 1996).

A sociedade contemporânea está marcada pela mudança de paradigma na qual o processo produtivo está baseado no domínio e produção do conhecimento, fato este que permite que a chamemos de Sociedade do Conhecimento. Ela é intimamente influenciada pelos meios de comunicação e pelas tecnologias digitais, as quais permitem a configuração e promoção de novos espaços interativos, onde o indivíduo pode aprender e adquirir novas competências. Aretio (2007) salienta que a sociedade contemporânea, na realidade deve ser denominada de Sociedade da Aprendizagem, uma vez que a produção do conhecimento está tão suportada e acelerada pelas tecnologias digitais de forma que é imperioso que repensemos urgentemente o papel da escola e, principalmente, as formas de ensinar em face de tantas mudanças. Os aprendizes deste novo ambiente de aprendizagem devem ser pensados como sujeitos em busca de novas perspectivas e, segundo Bates (2006), devemos nos preocupar em pensar a Educação na perspectiva de uma sociedade do conhecimento, com uma nova economia, onde as pessoas devem desenvolver habilidades e competências para resolver problemas, possuir pensamento crítico, trabalhar de forma autônoma (aprendizes independentes), perceber o valor do trabalho coletivo, senso crítico e empreendedor, e possuir competências relacionadas ao uso da Internet e seus recursos. Este aprendizado através do ciberespaço deverá ter identidade e contexto específico, desenvolvidos com uma intenção clara para um aprendizado cooperativo.

Segundo Prensky (2001), hoje temos os nativos digitais sendo ensinados e tutelados por imigrantes digitais. $\mathrm{O}$ que significa que, os docentes não nasceram imersos no contexto de uso massivo de tecnologias e tiveram de

\footnotetext{
${ }^{1}$ Micromundo é um software que apresenta características de um sistema de autoria orientado a objetos, aliado à linguagem Logo. É um sistema aberto, de interface amigável e fácil interação e sua principal característica é a de possibilitar ao usuário resolver situações-problema e desafios em um ambiente de construção de projetos multimídia. Pedagógicamente, a estrutura do programa possibilita a interação com o conhecimento dentro de uma perspectiva construtivista-interacionista, caracterizando-o como um software educacional metodologicamente adequado ao desenvolvimento de projetos pedagógicos abrangendo todas as áreas do currículo escolar.

( http://pt.wikipedia.org/wiki/MicroMundos)
} 
desenvolver competências e habilidades para poder adaptar-se a este novo contexto. Logo, a percepção não é a mesma. O desafio é grande e temos de vencer preconceitos antes de tudo. A Internet está trazendo mais do que uma revolução tecnológica, uma revolução comportamental, vindo para facilitar a comunicação entre as pessoas e criando uma nova percepção relacionada aos saberes, competências e habilidades. Ao participar ativamente da aquisição desses conhecimentos, o aluno terá a possibilidade de se integrar e assimilar com mais facilidade tudo aquilo que estiver aprendendo Mas deverá ter cautela e verificar de que maneira irá utilizar tudo àquilo que estará aprendendo, assim saberá se vale à pena aprender tal informação. Importante salientar o papel da família, dos pais, da escola na supervisão das atividades das crianças e adolescentes face ao conteúdo disponibilizado na rede. Importante educar esta geração para pesquisar de maneira crítica e seletiva. A geração Zappiens geralmente acredita que o que está na Internet é verdadeiro. Além dos desafios de assimilação da tecnologia os professores têm a frente o desafio do uso pedagógico e critico dos conteúdos e recursos da rede. Ferramentas para auxiliar pais e escolas a controlar os conteúdos e acesso a sites estão cada vez mais difundidos. Considerando a facilidade de se criar espaços de discussão no MSN (Microsoft Service Network), o uso cotidiano de ferramentas de busca tal como o GOOGLE, (foi criado um novo verbo "googlar" como sinônimo de pesquisas na rede Internet), o espaço de relacionamento criado pelas comunidades do ORKUT, o uso cada vez mais disseminado dos WeBlogs ${ }^{1}$ (Blogs e seus correlatos), a disseminação de ambientes que permitem a criação de simulações de realidade virtual imersiva tal como o Second Life e o uso de salas de aulas virtuais em plataforma de suporte ao e-learning como o MOODLE e outros similares, pergunta-se: ainda existe espaço para se produzir softwares educacionais?

A reposta é sim, com certeza vamos precisar criar alternativas para serem incorporadas ao ciberespaço para auxiliar alunos e professores a produzirem conhecimento e entenderem o conhecimento existente. Em tempos de virtualidade a oferta de material digital será cada vez mais necessária.

Este artigo busca resgatar informações relacionadas ao software educacional desde os tutoriais simples até os mundos virtuais, analisando as possibilidades relacionadas à oferta da modalidade de Educação a Distancia que cada vez mais ocupa espaço na educação formal. Ao final apresentamos nossa percepção acerca das possibilidades e desafios para a pesquisa na área.

Este texto está dividido em 4 seções. A seção 2 apresenta uma visão retrospectiva dos softwares educacionais

\footnotetext{
${ }^{1}$ WeBlogs é uma página da Web cujas atualizações (chamadas posts) são organizadas cronologicamente de forma inversa (como um diário). Estes posts podem ou não pertencer ao mesmo gênero de escrita, referirse ao mesmo assunto ou ter sido escritos pela mesma pessoa. (Wikipedia)
}

visando contextualizar o leitor numa perspectiva histórica da evolução deste tipo de programa e as dificuldades encontradas na sua produção através dos tempos.

A seção 3 apresenta algumas considerações a respeito dos ambientes virtuais e discute os desafios e possibilidades para a comunidade de Computação no que tange a pesquisa aplicada a área de Educação a Distância.

Ao final são apresentadas as referências bibliográficas utilizadas para redação deste artigo.

\section{Os tipos de software educacionais: uma visão retrospectiva}

As taxonomias tradicionalmente utilizadas para classificar os softwares educacionais não deram conta da evolução rápida da tecnologia e dos projetos de sistemas. A integração de diversas características fez com que a divisão por categorias fosse abandonada. A taxonomia de Taylor famosa na década de 80 do século XX categorizava os programas em três grupos: tutor, tutelado e ferramentas. Esta taxonomia classificava o software a partir da perspectiva do computador e não do usuário. .Programas tutores eram aqueles que tutelavam o aprendizado do aluno, programas da categoria tutelados eram aqueles que permitiam ao aluno "programar" o computador para funcionar a partir da sua perspectiva e necessidades. Neste contexto estava o micromundo do LOGO, baseado nas idéias de Papert (1980). O grupo das ferramentas permitia a manipulação das informações através de programas específicos, como por exemplo, os editores de textos, planilhas, gerenciadores de banco de dados, pacotes gráficos e outros.

Bertoldi (1999) apresenta uma analise acerca desta taxonomia e discute os aspectos sugeridos por Campos em seu trabalho de avaliação de Qualidade de Software. Este trabalho permite ao leitor recuperar a perspectiva histórica e evolutiva da discussão da classificação dos softwares educacionais que tanto preocuparam a comunidade em um determinado momento da pesquisa em IE.

$\mathrm{Na}$ pesquisa de doutorado publicada em Giraffa (1999), é apresentada uma divisão dos softwares educacionais em dois grandes grupos: CAI (Computer Aided Instruction), fundamentado na teoria behavioristacomportamentalista e os Ambientes de Aprendizagem Interativa fundamentados na teoria cognitivistaconceitual piagetiana. Dez anos transcorreram e esta classificação ainda permanece válida, apenas incorporando ao segundo grupo a questão sócio-interacionista baseada nas idéias de Vygotsky, que embasam fortemente os projetos de plataformas para construção de ambientes virtuais de suporte ao ensino e a aprendizagem.

Os CAI são programas que possuem uma modelagem menos complexa do que os programas da modalidade interativa. As diferenças mais profundas entre os ICAI (Intelligent Computer Aided Instruction) e os CAI tradicionais estão nas formas com que se concebem os seus 
projetos. Os CAI induzem o aluno a uma resposta correta mediante uma série de estímulos cuidadosamente planejados. Por outro lado, os ICAI pretendem simular algumas das capacidades cognitivas do aluno e utilizar os resultados como base das decisões pedagógicas a serem tomadas. No grupo dos CAI vamos encontrar as seguintes modalidades:

- Programas de reforço ou exercício - o aluno pratica e testa conhecimentos de forma dirigida e mais procedural. As versões mais atuais destes programas utilizam recursos hipermídia mantendo estas características. Alguns incorporam vídeos digitais com apresentações e explicações associadas a cada parte do conteúdo.

- Tutoriais - seguem o padrão de ensino da sala de aula tradicional onde o conteúdo é previamente organizado numa estrutura definida pelo professor e o aluno seleciona dentre as diversas opções disponíveis o conteúdo que deseja estudar. Mesmo aqueles que utilizam estrutura de hipermídia ou foram escritos em versão WEB, mantêm as características do ensino tradicional e não apresentam grandes revoluções, sob o ponto de vista pedagógico. Assim, o fato de ser um tutorial não significa que o software não seja bom ou não acrescente informações/conhecimento ao aluno. Este é um preconceito que não se justifica. Toda a modalidade de software educacional é boa se estiver devidamente contextualizada no projeto pedagógico do curso/aula. Não é software que vai fazer a diferença e sim a forma como o utilizarmos agregará ou não elementos importantes ao processo de ensino e de aprendizagem. Portanto, o software escolhido tem de ser resultado da estratégia docente e não o contrário.

- Jogos educacionais e as simulações - são modalidades que adquiriram uma projeção maior nos últimos anos devido ao desenvolvimento dos recursos de H\&S (hardware e software) disponíveis no mercado. As diferenças conceituais entre os jogos e as simulações podem ser caracterizadas pelo fato de que o jogo é um processo intrinsecamente competitivo (em que co-existem a vitória e a derrota) e uma simulação é a simples execução dinâmica de um modelo previamente definido. Os jogos educacionais são exemplos de ambientes de resolução de problemas que podem ser projetados e explorados com uma abordagem construtivista, o que os colocaria também na categoria 2 . Nos ambientes concebidos na abordagem construtivista/interacionista, existem ferramentas e possibilidades de combinações para que o aluno resolva um determinado problema. Os jogos apresentam restrições para a atividade do aluno, como por exemplo, a limitação de tempo e o objetivo a atingir. Está implícito um sentido de competição que pode ser explorada positivamente.

- A simulação implica em um modelo computacional que procura dar conta dos eventos que acontecem no ambiente. Os eventos acontecem de forma contínua em relação ao tempo e de forma discreta em relação às ações, uma vez que são interrompidos e retomados durante o processo. Muitos ambientes educacionais não são simulações, mas emulações da realidade, uma vez que não se utilizam de modelos computacionais.

Os bons programas de CAI permitem ao aluno vivenciar uma série de informações/conhecimentos relacionados às mais diversas áreas do conhecimento. Uma rápida visita a repositórios brasileiros, tal como:

RIVED (http://www.rived.mec.gov.br)

CESTA (http://www.cinted.ufrgs.br/CESTA/)

LabVirt (www.labvirt.fe.usp.br)

Oe3-tools (http://www.cesec.ufpr.br/etools/oe3)

Permitem que se encontre uma série de possibilidades gratuitas. Se o curso permitir o uso de programas escritos em inglês, alternativa interessante encontra-se em repositórios internacionais tas como:

MERLOT (http://www.merlot.org/merlot/)

CAREO (http://www.ucalgary.ca/commons/careo)

ARIADNE (http://www.ariadne-eu.org)

Wisc-Online (http://www.wisc-online.com)

Os repositórios mencionados acima incorporam o conceito atual de tratar o projeto de softwares educacionais na perspectiva de Objetos de Aprendizagem (OA), observando a questão do reuso e interoperabilidade. Segundo Weller, et al. (2003), um OA é uma parte digital do material da aprendizagem que se dirige a um tópico claramente identificável ou resultado da aprendizagem e tem o potencial reutilização em contextos diferentes. $\mathrm{O}$ trabalho de Monteiro (2006) apresenta uma reflexão interessante acerca da percepção do MEC e da comunidade que projeta softwares relacionados aos tipos de OAs. O conceito do que é um OA pode variar muito e considerar que OAs são apenas software é uma visão mais reducionista da questão. Quando o objeto de aprendizagem que é um software ele é por definição um software educacional. Logo ele poderá ser inserido em qualquer uma das categorias mencionadas.

Afirmar que é difícil encontrar um software educacional para uso nas escolas não é mais verdade. Existem muitos softwares educacionais nesta categoria ofertada de forma gratuita e organizada. Os repositórios "certificados" por alguma organização governamental ou universidade costumam ter um sistema de avaliação antes da sua disponibilização, fato este que agrega um filtro ao programa que, de certa forma o "qualifica". A grande preocupação dos pesquisadores e dos educadores em geral está associada à qualidade pedagógica do programa. Muitas ofertas são muito boas tecnicamente, possuem interfaces agradáveis, sofisticadas e deixam a desejar no na correção do conteúdo, na abordagem que utilizam ou na forma com que apresentam alguma espécie de avaliação.

Desde o primeiro tutorial criado pela marinha americana para ensinar procedimentos de segurança, desenvolvidos em interfaces orientadas a caracteres (em mainframes) até os sofisticados tutoriais hipermídia com vídeos e 
avatares que utilizam voz tanto para receber instruções como para enviar instruções um caminho de mais de 50 anos transcorreu.

Nesta evolução do software educacional, impactada, como não poderia deixar de ser, pelo avanço da tecnologia um conjunto de técnicas oriundas da Inteligência Artificial (IA) foi também incorporada. Estes sistemas que se utilizam de IA no seu projeto e implementação surgiram na década de 70 do século XX (Giraffa, 1999). Esta categoria de programas educacionais foi denominada de ICAI (Intelligent CAI).

Dentre os ICAI encontramos os Sistemas Especialistas (SE) voltados ao suporte de diagnóstico e tomada de decisão e os Sistemas Tutores Inteligentes (STI). Os STI são programas de computador que utilizam técnicas procedentes da IA para representar o conhecimento e ofertar algum grau de interação com o aluno. $\mathrm{O}$ objetivo fundamental dos STI é proporcionar uma instrução adaptada ao aluno, tanto no conteúdo como na forma, superando desta maneira alguns dos problemas mais cruciais do software educativo sempre enfrentou.

Neste sentido, os STI deveriam apresentar um comportamento o mais próximo possível ao de um professor humano. Porém, a realidade está muito distante de alcançar tal propósito. Existem muitas razões para que isto ocorra, entre elas referimos limitações em nível de hardware e software que não nos permitem colocar dispositivos que possam trabalhar com aspectos relativos aos sentidos do olfato, tato e visão. Um professor humano pode e leva em consideração tais estímulos para poder organizar seu trabalho junto ao aluno e, além disto, utiliza as saídas destes sentidos para fins de feedback (retroalimentação).

Temos um conjunto de teorias (umas mais trabalhadas do que outras), mas não temos ainda, uma resposta de como armazenamos, processamos e recuperamos informações no nosso cérebro. A resposta de como se estruturam tais aspectos é vital para a construção de um modelo de aluno e por conseqüência importantíssima para a construção de um STI. A grande diferença entre um STI para os CAI reside no fato de se criar o modelo do aluno. Ou seja, busca-se armazenar informações do aluno que utiliza o programa de maneira a ter o seu "perfil". Estas informações são utilizadas pelo software para customizar a forma como ocorrerá a interação com o aluno quando ele retornar a utilizar o programa. Importante destacar que se projeta um STI para permitir que o aluno vivencie situações diversas que o auxiliem a aprender determinado conteúdo. O princípio básico inerente aos STIs é que o aluno utiliza o sistema várias vezes e, a cada vez o programa é executado, ele se ajusta (interface, complexidade exercícios ofertados, etc.) conforme as informações armazenadas. Tudo que o usuário realizou na interação anterior (e está previsto como parâmetro para configurar o ambiente) é utilizado na próxima vez que o aluno usar o programa.
A técnica de IA diferencia-se da técnica utilizada em programas CAI. IA apresenta uma modelagem qualitativa. O que a torna vantajosa em relação ao CAI, uma vez que podemos simular o processo de solução de problemas. Desta forma podemos permitir que o aluno utilize um modelo de resolução de problemas e que este possa servir de base para se entender como aquele resolve os problemas propostos, utilizando parcialmente a assistência do ambiente.

No caso dos ICAI, se pretende que o próprio computador adote uma forma de conduta inteligente que permita controlar o processo de aquisição do conhecimento por parte do aluno. Os processos da máquina só podem operar baseando-se em operações explícitas e regras. A interação natural entre humanos (professor-aluno) envolve afetividade, o que já não se processa da mesma forma na interação entre máquina-humano (computador-aluno). Os computadores ainda não podem relacionar-se afetivamente com os seres humanos, cabendo às pessoas, na maioria das vezes, se adaptar ao "estilo da máquina" em vez dela adaptar-se à natureza do indivíduo, fato que ocorre naturalmente quando existe a interação entre humanos (professor-aluno). Os STI procuram esta adaptação e utilizam todas as técnicas de IA disponíveis para tanto. A pesquisa na área de afetividade em máquina e afetividade de máquina tem evoluído muito nos últimos dez anos. O trabalho de Bercht (2008) apresenta uma visão geral dos esforços despendidos neste sentido. Segundo Bercht, os computadores não podem se relacionar afetivamente de uma forma natural e a pesquisa na área neste momento trazem aspectos de funcionalidade que as emoções podem trazer.

A destreza e o conhecimento humano são baseados em crenças e juízo que, que apesar de serem difíceis de decompor, são fundamentais para modelar o processamento de informação humano. Sendo assim, quanto mais utilizamos computadores como ferramentas intelectuais mais dependemos das características formais e menos das dimensões táticas e interpretativas do conhecimento. Destacam-se a seguir alguns aspectos de qualidade dos sistemas educacionais que utilizam IA e que são considerados como de "senso comum" para quem trabalha nesta área:

Os sistemas necessitam incorporar componentes de IA e estes estão longe do trivial no que concerne à modelagem e implementação. Como todo software educacional sua qualidade depende da constituição de uma equipe interdisciplinar que possua expertise do conhecimento da área de aplicação (conteúdo), uma proposta pedagógica suportada por um aporte teórico oriundo da Educação/Psicologia e no que tange a implementação a equipe deverá possuir competências diversas, ainda mais que hoje a produção de um software requer um projeto que contemple diretivas oriundas da Engenharia de Software. Os repositórios e as plataformas para suporte as aulas virtuais necessitam de observar padrões internacionais 
que suportem o reuso e a interoperabilidade. A grande maioria dos sistemas é ou será acessada pela Internet, com interfaces web. $\mathrm{O}$ projeto de tais sistemas vai além da mera curiosidade de um programador iniciante. Isto faz parte da história da IE

- a modelagem do domínio do conhecimento, particularmente no que se relaciona às habilidades trabalhadas proceduralmente e de forma acessível ao estudante, está longe de apresentar uma solução satisfatória no que refere à representação do conhecimento. Se um sistema é usado para provar um nível do problema, então isto pode ser visto como uma fonte de resolução do problema e os resultados podem ser usados pelo módulo de ensino;

- o uso de técnicas de IA no que diz respeito aos aspectos pedagógicos ainda não é eficaz. Os sistemas necessitam capacidades que permitam construir uma estrutura com estratégia explícita de navegação selecionada a partir do aluno. Uma vez obtida esta estrutura, os resultados serão mais eficazes;

- tornar o conhecimento explícito e facilmente modificável para que o comportamento dos sistemas seja mais consistente e racional. Ao estudante pode ser permitida a interação com a base de conhecimento através da leitura, depuração e complementação de informações.

Acrescentar um I à sigla CAI não significa apenas agregar técnicas de IA para a construção de sistemas tutores, mas inclui trabalhar de forma interdisciplinar com as conquistas que outras áreas de pesquisa obtiveram em relação ao conhecimento da comunicação inteligente, tais como os avanços da psicologia e da pedagogia.

Os STI se modificaram muito desde a primeira proposta de Carbonel em 1972 (Giraffa, 1999) e sua "evolução" dá-se pela própria modificação dos recursos computacionais e amadurecimento do o papel de um software no contexto do processo de aprendizagem do aluno. E, também da revisão da atuação do professor.

A promessa de Carbonel e seus colegas não se cumpriu. Os STI não conseguiram fazer o acompanhamento no nível de refinamento esperado. De certa forma que bom que isto não aconteceu. $\mathrm{O}$ ensino mecanicista e controlado por estímulo-resposta a partir de um modelo estereotipado de comportamentos do aluno não poderia efetivamente se sobrepor. $\mathrm{O}$ mito do professor substituído pelo computador ameaçou uma geração de docentes e isto aconteceu devido ao desconhecimento das possibilidades e restrições dos sistemas computacionais. Àquilo que não se conhece bem se costuma atribuir mais ou menos possibilidades do que efetivamente é real. No caso dos softwares educacionais foi criada uma expectativa errônea. Os sistemas computacionais com técnicas de IA integradas não conseguiram funcionar de forma autônoma a partir de uma base expressa por regras de produção, crenças ou qualquer outro tipo de representação. Um sistema totalmente independente de supervisão humana não cumpriu de forma efetiva a supervisão do processo de apren- dizagem do aluno. Surge então a possibilidade de estender a arquitetura tradicional dos STI incorporando um agente/modulo "externo" ao sistema que representasse a intervenção humana do professor, tal qual acontece na situação presencial de sala de aula convencional. Raabe (2005) apresenta no seu trabalho de tese uma descrição dos Assistentes Inteligentes de Ensino (ITAs - Intelligent Teaching Assistant Systems) que exploram esta idéia de incorporar outro componente aos STI tradicionais, considerando que como objetivo fundamental dos ITA é assistir aos professores, reduzindo e automatizando as tarefas tediosas. Para isso, um ITA disponibiliza informações e serviços de assistência que permitem identificar e auxiliar os alunos individualmente facilitando na proposta de novos exercícios e materiais personalizados.

A arquitetura de um ITA, além dos três componentes tradicionais presentes em um STI tradicional (modelos do aluno, domínio, estratégia) inclui um módulo do professor e sua respectiva interface (Giraffa e Raabe, 2008). O módulo do professor é formado por ferramentas assistentes que possibilitam o monitoramento, a análise e a tomada de decisão para um determinado aluno em uma situação de aprendizagem. A interface é o meio por onde ele interage com o sistema.

Se compararmos a oferta de programas da categoria 1 aos aplicativos educacionais que incorporam IA ao seu projeto e podem ser classificados como STIs ou ITAs e, que efetivamente estão operacionais e disponíveis para acesso, vamos encontrar um numero bem menor de ofertas.

O site da equipe do CINTED possui bons exemplos de material sobre experimentos e projetos utilizando IA (http://www.cinted.ufrgs.br/CESTA/).

A biblioteca da SBC disponibiliza o acervo de todos os SBIE (Simpósio Brasileiro de Informática na Educação) e da RBIE (Revista Brasileira de Informática na Educação) onde podem ser acessados os projetos envolvendo STIs e ITAs. (http://bibliotecadigital.sbc.org.br)

Um aspecto importante a destacar é que estamos considerando até este momento os softwares que são desenvolvidos especialmente para apoio pedagógico/educacional. Taylor (1980) quando lançou sua taxonomia já destacava a possibilidade de se utilizar softwares projetados para outras atividades com finalidade educacional. Em (Giraffa, 1999) já havíamos mencionado que esta situação já ocorria freqüentemente e destacamos que qualquer software pode ser utilizado para fins educacionais desde que ele seja devidamente contextualizado no projeto pedagógico do curso/aula. Desta maneira, decidir se um software é ou não pedagógico envolve aspectos mais abrangentes do que o simples projeto. Qualquer programa pode vir a ser educacional desde que o professor crie uma estratégia metodológica para explorá-lo de acordo com seus objetivos educacionais. 
Esta possibilidade começou com os editores de textos utilizados para apoio ao ensino de línguas (Portuguesa e estrangeiras), planilhas eletrônicas usadas para apoiar as aulas de Matemática, Física e outras; gerenciadores de banco de dados organizando informações relacionadas as disciplina de História e Geografia, os slides do PowerPoint fornecendo funcionalidades que permitem a criação de jogos simples para uso pedagógico e assim por diante.

A evolução da tecnologia e o uso cada vez mais freqüente e diria quase absoluto de aplicações na Web possibilitaram que ferramentas e serviços também fossem percebidos como possibilidades para uso educacional.

Os jogos de ultima geração utilizando tecnologia de agentes e alta qualidade gráfica nas suas interfaces, tal como o The Sims são analisados na pesquisa de Kruger (2004), no que concerne aos aspectos educacionais deste tipo de ambientes, desenvolvidos com fins comerciais. , Na próxima seção apresentamos algumas reflexões acerca do uso educacional dos WeBlogs e dos mundos virtuais. como novos espaços de aprendizagem criados pelo ciberespaço.

\section{WeBlogs, mundos Virtuais e o ciberespaço}

A origem o conceito de WeBlogs, consiste na união das palavras Web (rede) e $\log$ (registro). Independente do tipo de conteúdo apresentado, os WeBlogs se transformaram em um veículo de expressão nos mais variados gêneros conforme Orihuela (2006). Fundamentados no conceito da simplicidade, os Blogs atingiram um rápido crescimento, pois os autores não precisam de praticamente nenhum conhecimento técnico. Mesmo sem conhecer a linguagem $\mathrm{HTML}^{1}$ os internautas podem publicar textos, fotos e vídeos através dos Blogs. Além de fácil manipulação, permitem rápidas atualizações. Baseado no principio de microconteúdo e atualização freqüente no artigo de Primo e Recuero (2003), o sistema permite uma escrita coletiva, pois todas as internautas podem assumir o papel de colaboradores, basta que o visitante escreva comentários sobre os assuntos (posts) publicados no Blog. "Os Blogs são o primeiro passo para que todas as pessoas alfabetizadas tenham sua própria plataforma no mundo“. (Amorin; Vieira, 2006).

Segundo Rodrigues (2006), o Blog é uma ferramenta que possibilita a integração de potencialidades que a Internet pode oferecer. Por ser simples na sua utilização, em sala de aula favorece a organização e disseminação de

${ }^{1}$ Derivado da palavra inglesa Hypertext Markup Language, que significa Linguagem de Marcação de Hipertexto é uma linguagem de marcação (conjuntos de códigos criados para serem lidos por computadores) utilizada para produzir página na Internet. Documentos HTML podem ser interpretados(lidos) por navegadores também chamados de Browser (são programas que utilizados para traduzir as páginas em HTML e outras tecnologias desenvolvidas para a internet). Internet Explorer, Fire Fox são exemplos de navegadores. (http://pt.wikipedia.org/wiki/) com adaptações da autora informações entre professores e alunos. Com o crescimento da Blogosfera ${ }^{2}$ os Blogs formaram diversas categorias como: Blogsite ${ }^{3}$, Bblooks ${ }^{4}$, EduBlogs/EBlogs ${ }^{5}$, FoodBlogs ${ }^{6} \cdot$ FotoBlogs $^{7}$, MediaBlogs ${ }^{8}$, MoBlogs ${ }^{9}$, Tech$B \log s^{10}$, VBlogs/VideoBlogs ${ }^{11}$ entre outros.

Os Blogs vão muito além da divulgação de informação. Se bem utilizados e explorados podem ser poderosas ferramentas de aprendizado, dentre as diversas possibilidades pedagógicas destaca-se a facilidade de comunicação entre professores e alunos.

Para melhor entendimento de como funciona este espaço de interação virtual criou-se um blog para apoiar as discussões entre o professor e seus alunos, bem como, entre os alunos e a monitoria da disciplina de Cálculo (http://blogdocalculo.blogspot.com/) onde se disponibilizou diversos links sobre os assuntos Matemática e Cálculo. O Blog criado por Fortes e Giraffa (2009), vide figura 1, foi utilizado como elemento adicional de suporte ao processo de ensino e de aprendizagem dos conteúdos desta disciplina. A figura 1 apresenta a tela do blog, o qual pode ser acessado pela Internet e encontra-se aberto para uso.

Novamente temos uma aplicação que não foi criada, para fins educacionais sendo amplamente exploradas por professores e alunos sem grande ou nenhuma experiência ou background de programação.

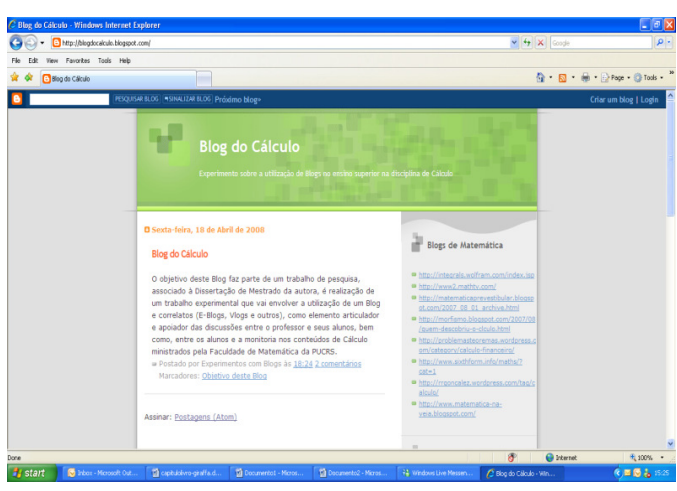

Figura 1: Interface do blog de Cálculo criado por Fortes e Giraffa (2009)

\footnotetext{
${ }^{2}$ Blogosfera: Universo dos blogs existentes na internet (CIPRIANI, 2006)

${ }^{3}$ Blogsite: híbrido de site e blog. Geralmente sites que possuem blog.

${ }^{4}$ Blooks: união das palavras blog e book. São livros criados com base nos posts de algum blog famoso. E nele inseridos capítulos do livro como posts (CIPRIANI, 2006)

5 EduBlogs/EBlogs: blog como ferramenta de docência, aprendizagem e investigação. (ORIHUELA, 2006)

${ }^{6}$ FoodBlogs: blog que apresentam o conteúdo sobre gastromonia.

${ }^{7}$ FotoBlogs: o conteúdo consiste em fotografias ao invés de textos (ORIHUELA, 2006).

${ }^{8}$ MediaBlogs: o conteúdo é sobre os meios de comunicação (ORIHUELA, 2006).

9 MoBlogs: blogs mantidos pela transmissão de arquivos via telefones

${ }^{10}$ Techis.

${ }^{11}$ VBlogs/VideoBlogs: os posts são baseados em vídeos ao invés de textos (CIPRIANI, 2006)
} 


\subsection{Os mundos virtuais como espaço de aprendizagem}

O Second Life (SL) é uma plataforma virtual de realidade digitalizada em 3D (três dimensões), do tipo MMORPG (Massive Multiplayer Online Role-Playing Game - Jogo de interpretação online massivo para múltiplos jogadores). Apesar de parecer um jogo, existe uma diferença entre o SL e um jogo de computador tradicional (game) uma vez que não existem objetivos definidos e não há regras para se jogar/utilizar o software. No entanto, existem regras para a sobrevivência e boa conduta dentro do espaço virtual. A regulação é feita através do manual dos "Seis Pecados Capitais": intolerância, moléstia, ataque, revelações, indecência e perturbação da paz, onde seus criadores apostam na transmissão de valores e bons hábitos de senso comum através da do estabelecimento de regras de conduta para regular as ações dos avatares.

Para que possamos utilizar o SL para fins educacionais, deveremos descobrir primeiramente qual será a melhor maneira de utilizá-lo, como iremos adequar essa nova tecnologia para a educação. A plataforma SL oferece possibilidades para utilização na área da Educação, mas é importante saber exatamente o que desenvolver para oferecer aos alunos e de preferência, continuar atualizando essas atividades e inserindo conteúdos para que a área disponibilizada pela instituição, não seja mais um local no SL sem funcionalidade. Os experimentos já realizados no SL, tal como o trabalho de Cunha e Giraffa (2009), permitiram aos alunos da disciplina de Historia da Matemática vivenciar questões relacionadas, por exemplo, a teoremas e contexto histórico relacionados a conteúdos que tradicionalmente são apenas apresentados em forma algébrica, como o caso do Teorema de Pitágoras.

No segmento de mundos virtuais encontramos o projeto SLoodle que possibilita o acesso a alguns recursos do ambiente MOODLE (www.moodle.org) diretamente do ambiente Second Life. É possível, por exemplo, estabelecer um chat entre os dois sistemas, ou mesmo adicionar textos a sua página do MOODLE utilizando apenas o Second Life. Também há a possibilidade de acessar a página MOODLE utilizando o browser de acesso à internet do SL.

As opções para uso, cada vez mais crescentes, de mundos virtuais MMOs - (Massively Multiplayer Online) são diversas. O professor/aluno pode escolher entre ambientes proprietários ou gratuitos dentre ambientes virtuais as diversas destacamos:

- Kaneva (http://www.kaneva.com/) é um ambiente virtual 3D, onde você pode manter uma rede social, ter amigos virtuais e reais, fazer interações $3 \mathrm{D}$, colocar suas fotos e vídeos e ter sua vida no mundo online
- HIPIHI (http://www.hipihi.com) é um mundo virtual, muito parecido com o Second Life, mas que segue as tradições de seu país de origem, a China. Construído com cenários cheios da mística oriental, o novo mundo virtual traz para dentro do computador templos budistas, dragões, fengshui e motivos relacionados com os Jogos Olímpicos de Pequim 2008.

- IMVU (http://www.imvu.com) funciona como um Messenger, mas nele você será um personagem virtual. O IMVU é como a evolução dos Messenger em que você cria o seu personagem virtual e começa a bater papo com amigos, família ou quaisquer outros personagens que você queira fazer amizades.

- Metaplace (https://www.metaplace.com) é uma plataforma em 3D em que os usuários podem criar e determinar algumas regras do jogo. Existem duas propostas de realidade virtual, a Metaplace Sytle Home e a Fantasy Style Home, com vias de ser criado um novo mundo que será chamado de Sci-Fi Style Home.

- ClubPenguin (http://www.clubpenguin.com) criado para crianças entre 6 e 14 anos de idade. Assim, uma das grandes preocupações dos criadores do site tem sido a segurança das crianças online. Para tanto, foi introduzida uma série de ferramentas no jogo, incluindo um "modo de bate-papo SuperSeguro", no qual os usuários podem escolher suas falas em um menu pré-definido de frases; um sistema de filtro de palavras para prevenir o uso de termos inadequados e a divulgação de informações pessoais; e uma equipe de moderadores online (com a ajuda de jogadores veteranos), que monitoram o jogo. $\mathrm{O}$ sucesso do jogo original (em inglês) foi tamanho que a empresa foi comprada pela Disney. No Brasil o clube é reconhecido por algumas escolas de ensino fundamental e suas atividades mencionadas em sala de aula.

Uma tendência que se observa é disponibilizar ambientes que não necessitam de qualquer instalação para serem acessados, como aqueles que executam sobre a plataforma Flash. Desenvolver softwares cada vez mais accessíveis via um browser na Web, sem necessidade do usuário preocupar-se com a instalação, deve fazer parte do conjunto de requisitos a ser incorporado ao projeto dos softwares educacionais.

Novamente observa-se o uso de aplicações criadas para fins de entretenimento serem utilizadas com fins educacionais em virtude da criatividade do professor. Importante destacar que estes ambientes construídos com a finalidade original de lazer possuem muitas funcionalida- 
des que podem ser organizadas de maneiras diversas e isto que permite sua exploração pedagógica.

\section{Considerações finais}

Quando se analisa os tipos de software educacionais e se critica suas eventuais limitações deve-se cuidar a questão do contexto tecnológico e as crenças de Educação que se professava na época do seu projeto. Os primeiros CAIs são reflexos de uma concepção de educação tecnicista, pós II Guerra Mundial, onde o mundo se reconstruía. A produção industrial em escala necessitava de um conjunto de competências por parte das pessoas que atuariam no mercado que privilegiavam a observação, memória, identificação, classificação e seleção. Não é de se estranhar que a escola optasse por uma abordagem mais instrucionista do que reflexiva para o processo de ensino. Uma vez que o sujeito iria trabalhar em uma linha de produção. Atualmente mudou drasticamente o perfil e a competências necessárias para se atuar no mercado de trabalho.

Vivemos num mundo que evolui velozmente, onde as tecnologias se obsoletam rapidamente e o conhecimento que vale hoje poderá não ser útil amanhã, pelo menos de forma direta. O Homo Zappiens aprende muito cedo, segundo Veen e Vrakking (2009), e há muitas fontes de informação que podem defender verdades diferentes e podem mudar de forma constante. O conhecimento está em expansão e vai requerer atualização constante a atitude de eterno aprendiz.

As TDs mudaram a forma como percebemos o mundo e nos comunicamos. Certamente elas mudaram a forma como o Homo Zappiens constrói e processa informação. No entanto, tudo é muito recente e não sabemos o real impacto de tudo isto. Sabemos com certeza que esta nova geração processa e constrói conhecimento de maneira diversa daquela que seus pais e professores, todos (ainda) imigrantes digitais. A escola tradicionalmente é o ultimo reduto a incorporar novidades, especialmente ligadas à tecnologia, comparando com os demais setores da sociedade. Até os dias de hoje isto não foi um fator perturbador ou interveniente da qualidade do serviço que ela presta à sociedade: educação. Certamente isto vai mudar e rapidamente.

Cabe ao professor criar novas metodologias, explorar os espaços virtuais e suas possibilidades. A Matemática é uma das áreas onde se encontra o maior número de softwares disponíveis para auxiliar no processo de ensinoaprendizagem, todavia grande variedade não implica, necessariamente, em qualidade. Muitos programas possuem conteúdo mal formulado, problemas na execução do sistema, interfaces (telas) confusas e assim por diante. Novamente o papel do professor é fundamental.

O desafio dos docentes que atuam no século XXI é transpor as idéias cristalizadas do conceito tradicional de professor e de universidade para o conceito mais atual e amplificado, preconizado por Cazalis (2007). De acordo com Cazalis o estudante compreende ao mesmo tempo as razões pelas quais lhe é proposta uma formação teórica, com problemas oriundos da prática profissional, propiciando a vivência do paradigma de auto-aprendizagem, tão importante numa sociedade em que o conhecimento aumenta de forma exponencial. A prática limitada e a percepção restrita do potencial das ferramentas de comunicação e dos recursos disponibilizados em AVEAs, para uso educacional, também é um fator limitante para se criar inovações no âmbito da Educação. Uma vez que os projetos pedagógicos acabam se restringindo ao universo de conhecimento tecnológico do professor projetista. Daí a necessidade de programas que ampliem a formação docente no que concerne ao uso de tecnologias, permitindo que ele crie novas possibilidades pedagógicas relacionadas ao modelo da cibercultura.

Que tipo de softwares vamos necessitar? A disseminação de uso de dispositivos móveis que integram diversas tecnologias e a idéia de Clouding Computing apontam algumas direções. Nos próximos anos deveremos ouvir muito os termos "computação nas Nuvens", "cloud computing" e "SaaS - Software-as-a-Service". A idéia geral é que cada vez mais as informações estarão disponíveis e mais pessoas terão acesso a essas informações, graças à disponibilização de serviços on-line, muitos gratuitamente, e que devem baratear o preço dos computadores, inclusive, aumentando a presença on-line de pequenas empresas e fornecedores de serviços. O termo refere-se à possibilidade de utilizarmos computadores menos potentes que podem se conectar a Web e utilizar todas as ferramentas on-line, seguindo o exemplo que o Google propõe com o Google Docs, Gmail e tantas outras aplicações. Assim, o computador seria simplesmente uma plataforma de acesso às aplicações, que estariam em uma grande nuvem - $a$ Internet. (http://www.undergoogle.com/).

Vamos necessitar cada vez mais de ambientes/ferramentas/plataformas que sejam de fácil manuseio, que permitam criar aplicações de aparência "profissional".

Incorporando vídeos, áudios, textos, imagens e tudo que se puder digitalizar. Mas especialmente precisaremos que estes novos serviços/programas sejam flexíveis e permitam a professores e alunos criarem aplicações que se adéquiem aos seus projetos educacionais. Um grande erro e básico que se comete ao projetar softwares, especialmente para ensino infantil, fundamental e médio, é pensar que por termos sido alunos de tais séries somos aptos a desenvolver aplicativos somente porque fomos sujeitos de um processo.

Vimos reiteradamente reforçando e não estamos sozinhos, que somente equipes interdisciplinares com atitude transdisciplinar poderão dar conta destes desafios. Equipes com diferentes competências no que tange a Computação, Educação, Psicologia, Comunicação sem esquecerse da área de aplicação (conteúdo) do sistema. 
Precisamos de aplicações para Matemática, Física, Inglês, Português, História e todas as demais áreas do conhecimento.

O trabalho de Weller (2004) já apontava os desafios e dilemas da comunidade para produção de OAs. Reutilizar um software educacional não é uma tarefa simples. O reuso do código (estrutura do programa) é muito mais fácil do que o reuso da informação nele contida, sempre haverá a necessidade de ajustar parâmetros em função do uso pedagógico e isto não é possível de se fazer sem a intervenção humana.

A questão é que produzir um software de qualidade custa muito e leva tempo. A maioria dos projetos oriundos de pesquisa não fica com acabamento para ser colocado em produção e venda. E quando é vendido o público a que se destina tem um poder de compra baixo. Lembra que falamos Português e interfaces nesta língua não vendem com interfaces em Inglês, cujo mercado é mundial. Logo, o custo de projeto/implementação fica difícil de diluir. Não queremos com isto desestimular a produção e a pesquisa de tais softwares e sim apenas apontar aspectos para reflexão. Produzir ambientes/ferramentas/plataformas como mencionado anteriormente vai requerer pesquisa integração de resultados de diversas áreas da Computação.

"Em tempos de mudança, aqueles que aprenderem herdarão a Terra, enquanto aqueles que já aprenderam encontrar-se-ão esplendidamente equipados para lidar com um mundo que não mais existe." Eric Hoffer

\section{$\underline{\text { Agradecimentos }}$}

Todo trabalho de pesquisa não é realizado de forma solitária. Meus orientandos ao longo destes anos foram parceiros importantes na construção de idéias e resultados, alguns deles se tornaram amigos e outros filhos que a vida me deu. Meus agradecimentos a todos e em especial para Sabrina Marczak e André Raabe.

\section{Referências}

ARETIO. G, L. (coord.) Ruiz Corbella, M.; Domínguez Fajardo, D. De la educación a distancia a la educación virtual. Barcelona, Ariel, 2007.

BATES, T. Managing change for sustainability in Strategies for Sustainable Open and Distance Learning London/New York: Routledge/Commonwealth of Learning, 2006.

BERCHT, M. Towards a Model that Considers the Student's Affective Dimensions in Intelligent Tuto- ring Systems. In: Rosa Maria Viccari, Patricia Augustin Jaques, and Regina Verdin. (Org.). AgentBased Tutoring Systems by Cognitive and Affective Modeling. 1 ed. Hershey: IGI GLoBal, 2008, v. , p. 178-200.

BERTOLDI, S. Avaliação de Software Educacional: Impressões e Reflexões. Florianópolis, PGCC/UFSC, 1999.

CAZALIS, Pierre. Menos aula, mais conhecimento. PUCRS Informação, Porto Alegre, ano 30, n. 135, p. 24-25, jun./ago. 2000.

CIPRIANI, F. Blog Corporativo. SP: Novatec, 2006.

CUNHA P.F.V. Uma Investigação Acerca Do Uso Educacional Do Ambiente Second Life No Ensino De Matemática. 2009. Dissertação (Mestrado Em Ciências e Educação Matemática) - Pontifícia Universidade Católica do Rio Grande do Sul.

ELIAS, H. Néon Digital: Um discurso sobre os ciberespaços. Covilhã-Portugual: Livros Labcom, 2008. (PDF disponível em http://www.livroslabcom.ubi.pt/coleccoes.html - acessado em março de 2009).

FORTES, L.. Blogs e seu uso educacional no ensino de Matemática. 2009. Dissertação (Mestrado Em Ciencias e Educação Matematica) - Pontifícia Universidade Católica do Rio Grande do Sul.

GIRAFFA, L.M.M. Uma arquitetura de tutor utilizando estados mentais. Porto Alegre: PGCC/UFRGS (Tese de Doutorado), 1999.

GIRAFFA, L. M. M.; RAABE, A. L. A. Cognitive Models Applied to Built Intelligent Educational Applications. In: Rosa Maria Viccari; Patricia Agustin Jacques; Regina Verdin. (Org.). AgentBased Tutoring Systems by Cognitive and Affective Modeling. 1 ed. New York: Herschey, 2008, v. 1, p. 114-134.

LÉVY, P. O que é o virtual. SP: Editora 34, 1996.

LÉVY, P. Cibercultura. SP: Editora 34, 2000.

FORTES, L.. Blogs e seu uso educacional no ensino de Matemática. 2009. Dissertação (Mestrado Em Ciências e Educação Matemática) - Pontifícia Universidade Católica do Rio Grande do Sul. 
MONTEIRO, H. P. et al. Metodologia de Desenvolvimento de objetos de aprendizagem com foco na aprendizagem significativa. XVII Simpósio Brasileiro de Informática na Educação, 2006.

ORIHUELA, J. L. La Revolución de Los Blogs. Madrid: La Esfera de los Libros, 2006.

PAPERT, S. Mindstorms: children, computers and powerful ideas. New York: Basic Books, 1980.

PRENSKY, M. Digital Natives, Digital Immigrants. In: The Horizon, MCB University Press, Vol. 9 No. 5, October 2001.

PRIMO, A.F.T. RECUERO, R.C. Hipertexto cooperativo: uma análise da escrita coletiva a partir dos Blogs e da Wikipédia. Revista Famecos, Porto Alegre, dezembro 2003.

PIAGET, J. A psicologia da Criança. Rio de Janeiro: Bertrand Brasil, 2001.

RAABE, A. L.A. Uma Proposta de Arquitetura de Sistema Tutor Inteligente baseada na Teoria das Experiências de Aprendizagem Mediadas. Porto Alegre: PGIE/UFRGS (Tese de Doutorado), 2005.

RODRIGUES, C. Blogs e a Fragmentação do Espaço Público. Covilhã-Portugual: Livros Labcom, 2006. (PDF disponível em http://www.livroslabcom.ubi.pt/coleccoes.html - acessado em março de 2009)

SCHITTINE, D. Blog comunicação e escrita intima na internet. Rio de Janeiro: Civilização Brasileira, 2004.

TAYLOR, R., P. The Computer in the School: Tutor, Tool, Tutee, New York: Teachers College Press, 1980.

VEEN, W., VRAKKING, B. Homo Zappiens Educando na Era Digital. Porto Alegre: ARTMED, 2009.

VYGOTSKY, L.V. Pensamento e Linguagem. São Paulo: Martins Fontes, 1999.

WELLER ate la. Putting the pieces together: What working with learning objects means for the educator. (disponível em http://iet- staff.open.ac.uk/m.j.weller/elearn.doc.-acessado em março 2009)

WELLER, M. Learning objects and the e-learning cost dilemma. Open Learning, Volume 19, Number 3, November 2004, pp. 293-302(10). 